\title{
CARACTERIZAÇÃO COMERCIAL DAS INSTITUIÇÓESS DE LONGA PERMANENCIA DE IDOSOS E DE SEUS ENFERMEIROS EMPREENDEDORES NO ESTADO DE SÃO PAULO, BRASIL
}

\author{
COMMERCIAL CHARACTERIZATION OF LONG-TERM \\ CARE FACILITIES FOR THE ELDERLY PEOPLE AND THEIR \\ ENTREPRENEURAL NURSES IN THE STATE OF SÃO PAULO, BRAZIL
}

\author{
CARACTERIZACIÓN COMERCIAL DE LOS HOGARES PARA \\ ANCIANOS Y SUS ENFERMERAS EMPRESARIAS EN EL ESTADO DE \\ SÃO PAULO, BRASIL
}

Rosana Maria Barreto Colichi*

Silvana Andrea Molina Lima**

\begin{abstract}
RESUMO
Objetivo: Caracterizar no âmbito comercial as instituições de longa permanência de idosos no Estado de São Paulo e aquelas constituídas por enfermeiros descrevendo o perfil dos enfermeiros empreendedores. Material e Método: Pesquisa transversal quantitativa, com coleta em bancos de dados da Junta Comercial do Estado e do Conselho Regional de Enfermagem (COREN) de 661 empresas registradas até junho/2017, sendo analisada a distribuição da frequência simples e relativa das variáveis. Resultados: A maioria das ILPI's foi registrada a partir de 2011 (61,3\%), na forma de sociedade de responsabilidade limitada (55,5\%), com capital social de até $\mathrm{R}$ \$ 50.000,00 (72,3\%) e faturamento anual de até R \$ 360.000,00 (69,9\%). Elas estáo presentes na maioria dos municípios paulistas, mas com maior concentração na cidade de São Paulo (36,8\%). Apenas 19,7\% das empresas foram constituídas por enfermeiros, com menor capital inicial e faturamento anual. Predominam enfermeiras empreendedoras mulheres (76,7\%), que constituíram empresas após seis anos do registro no COREN, o que ocorreu a partir de 2011 (46,0\%). Conclusôes: O número reduzido de ILPI's geridas por enfermeiros refletem o ensino voltado à carreira hospitalar, revelando a necessidade desenvolver habilidades empreendedoras na graduação, o que repercurtirá nesse novo papel ao garantir melhores cuidados à população envelhecida nas ILPI's.
\end{abstract}

Palavras-chave: Envelhecimento; Instituiçáo de longa permanência de idosos; Enfermagem; Contrato de risco, Empresa de pequeno porte.

\footnotetext{
*Administradora. Doutora em Gerenciamento de Serviços de Saúde e Enfermagem (FMB-UNESP), Universidade Estadual Paulista Júlio de Mesquita Filho - UNESP, Botucatu, SP, Brasil. ORCID: https://orcid.org/0000-0002-8765-3965. Email: rosana. barreto-colichi@unesp.br. Autor correspondente.

**Enfermeira. Professora Associada do Departamento de Enfermagem (FMB-UNESP), Universidade Estadual Paulista Júlio de Mesquita Filho - UNESP, Botucatu, SP, Brasil. ORCID: https:/orcid.org/0000-0001-9945-2928. Email: silvana.molina@ unesp.br
} 


\section{ABSTRACT}

Objective: To characterize, from a commercial perspective, the long-term care facilities (LTCFs) for the elderly in the State of São Paulo and those consisting of nurses by describing the profile of entrepreneur nurses. Materials and Methods: Quantitative cross-sectional research, using data collection in databases of the State Commercial Board and the Regional Nursing Council (COREN) of 661 companies registered until June 2017, analyzing the distribution of the simple and relative frequency of the variables. Results: The majority of LTCFs were registered from 2011 (61.3\%) in the form of limited liability company (55.5\%), with a share capital of up to $\mathrm{R} \$ 50,000.00$ (72.3\%) and annual revenue of up to $\mathrm{R} \$ 360,000.00$ (69.9\%). They are present in most municipalities of São Paulo State, but with greater concentration in the city of São Paulo (36.8\%). Nurses, with lower initial capital and annual revenue, constituted only $19.7 \%$ of the companies. There is a predominance of entrepreneur nurses (76.7\%), who founded companies after six years of registration in the COREN, which occurred in 2011 (46.0\%). Conclusions: The reduced number of LTCFs managed by nurses reflects training aimed at the hospital career and highlights the need to develop entrepreneurial skills in undergraduate courses, which will impact on this new role by ensuring better care for the aging population at the LTCFs.

Key words: Aging; Homes for the aged; Nursing; Entrepreneurship; Small Business.

\section{RESUMEN}

Objetivo: Caracterizar, en el ámbito comercial, los hogares para ancianos en el Estado de São Paulo y los integrados por enfermeras, describiendo el perfil de enfermeras emprendedoras. Material y Método: Investigación transversal cuantitativa, con recopilación en bases de datos de la Junta Comercial del Estado y el Consejo Regional de Enfermería (COREN) de 661 empresas registradas hasta junio de 2017, analizando la distribución de la frecuencia simple y relativa de las variables. Resultados: La mayoría de los hogares para ancianos se registraron a partir de 2011 (61,3\%), en forma de sociedad de responsabilidad limitada (55,5\%), con un capital social de hasta $\mathrm{R} \$ 50.000,00(72,3 \%)$ e ingresos anuales de hasta $\mathrm{R} \$ 360.000,00$ (69,9\%). Estos están presentes en la mayoría de los municipios del Estado de São Paulo, pero con una mayor concentración en la ciudad de Sáo Paulo (36,8\%). Sólo el 19,7\% de las empresas estaban constituidas por enfermeras, con un capital inicial y unos ingresos anuales más bajos. Predominan las enfermeras emprendedoras (76,7\%), que formaron empresas después de seis años de registro en COREN, lo que ocurrió en 2011 (46,0\%). Conclusiones: El número reducido de hogares para ancianos gestionados por enfermeras refleja la enseńanza dirigida a la carrera hospitalaria, lo que revela la necesidad de desarrollar habilidades empresariales en los cursos de pregrado, lo que tendrá un impacto en este nuevo papel al garantizar una mejor atención para el envejecimiento de la población en los hogares para ancianos.

Palabras clave: Envejecimiento; Hogares para ancianos; Enfermería, Contrato de riesgo; Pequeńa empresa.

Fecha recepción: 26/09/2019

\section{INTRODUÇÁO}

O Instituto Brasileiro de Geografia e Estatística (IBGE) aponta que a expectativa de vida ao nascer em 2.000 era de 69,83 anos no Brasil. Em 2030, as projeçôes indicam que essa expectativa será de 78,64 anos no Brasil ${ }^{(1)}$.

Correlacionada a essa realidade, em 2000 a população com mais de 65 anos de idade representava $5,61 \%$ do total de brasileiros. A
Fecha aceptación: 01/06/2020

projeção para o ano de 2030 é que essa população chegue a $13,54 \%$ e em 2060, o número de idosos deve triplicar, alcançando taxas de $25,49 \%$ no Brasil $^{(1)}$.

Essa variação de estrutura etária trará impactos econômicos devido ao aumento na fabricação de produtos farmacoquímicos, farmacêuticos e nutricionais, ampliação da saúde privada e intermediação financeira, seguros e previdência complementar $^{(2)}$. 
Naárea da saúde, o envelhecimento populacional brasileiro tem sido preocupação a alguns anos, tendo em vista os reflexos no aumento da demanda no cuidado dos idosos. Além de formas mais eficientes de financiar e prover os serviços de saúde para sua população, buscam-se novos modelos de atenção à saúde para idosos, cujas propostas de linha do cuidado para esse segmento tenham como foco a promoção e a prevenção da saúde, evitando a sobrecarga do sistema de saúde ${ }^{(3,4)}$.

Paralelamente, as dinâmicas sociais atuam fortemente nesse cenário e devem ser levadas em consideração. Pesquisas internacionais mostram novos arranjos familiares, como as opçóes pessoais em se manter sozinhos, a monoparentalidade, a homoparentalidade, casais sem filhos, entre outros. Atuais estilos de vida dos jovens, a diversidade e os novos papéis de gênero também são relatados. Além disso, a forte inserção da mulher no mercado de trabalho tem trazido alteraçóes significativas nas estruturas familiares. Todas essas mudanças sociais afetarão o cuidado informal dos idosos, que até o momento é realizado majoritariamente por familiares mulheres ${ }^{(5)}$. Há uma tendência, portanto, de haver lacunas no futuro acerca do cuidado do idoso.

Apesar disso, políticas públicas brasileiras, assim como em outros países da América Latina, não têm acompanhado essas transformaçóes demográficas e sociais ${ }^{(5)}$ e, considerando as características dos serviços de saúde no âmbito do SUS, a demanda é frequentemente superior à oferta, indicando a expansão progressiva na contratação complementar de instituiçôes privadas de cuidado de idosos.

Neste sentido, a contratação de serviços das instituiçóes privadas de forma complementar (regulamentada pelo Ministério da Saúde através da Lei no 8080/90) permitiria suprir a insuficiência dos serviços no setor público, que tenderá a aumentar significativamente com o envelhecimento populacional. Esse novo cenário de terceirização do setor da saúde e de transferência de fundo público para o setor privado ${ }^{(6)}$ pode ditar novos rumos ao mercado de trabalho do enfermeiro, com a abertura de novos campos de atuaçáo profissional ${ }^{(7)}$.

De acordo com a Agência Nacional de Vigilância Sanitária (ANVISA), as Instituiçóes de Longa Permanência de Idosos (ILPI) são consideradas organizaçôes governamentais ou não governamentais, de caráter residencial, que se destinam ao domicílio coletivo de pessoas com idade igual ou superior a 60 anos, com ou sem suporte familiar, em condição de liberdade e dignidade e cidadania ${ }^{(8)}$.

Pesquisas revelam que as instituiçôes privadas de cuidado de idosos nem sempre oferecem padrão de qualidade adequado, já que frequentemente são desprovidos de profissionais qualificados, não supervisionados por enfermeiros, atuando ilegalmente em muitos casos ou até na clandestinidade $^{(9-11)}$. Acrescenta-se ainda o fato de as mesmas ainda possuírem caráter assistencial, não sendo cadastradas como instituições de saúde e ainda desconsiderarem as legislaçóes descritas no Conselho de enfermagem ${ }^{(10)}$, apesar de muitos pesquisadores afirmarem que a assistência nas instituiçôes não deveria ser explicitamente social, já que é um serviço de interesse à saúde ${ }^{(1)}$.

Em contrapartida, a presença do profissional enfermeiro nas ILPI's e seu dimensionamento adequado têm sido relacionados à humanização ${ }^{(11)}$, ao aumento de indicadores de qualidade da assistência aos idosos presentes nas instituições de longa permanência de idosos (ILPI), tais como diminuição da prevalência de lesôes por pressão, perda de peso, uso de drogas psicóticas e de dispositivos vesicais ${ }^{(12)}$. Foram observados ainda correlaçóes ao menor número de internaçôes hospitalares e menor uso de contenção mecânica ${ }^{(13)}$.

Por conseguinte, quando ILPI's são constituídas e geridas por profissionais enfermeiros, sua presença, vocação de serviço e atuação tenderiam a garantir maiores chances, portanto, dessas empresas oferecerem serviços mais adequados e alcançar melhores padróes de atendimento que os idosos requerem. O enfermeiro, ciente de seu papel como responsável por uma ILPI, pode garantir açóes mais adequadas de sua competência, bem como das atividades da equipe de trabalhadores sob sua liderança, refletindo na relevância do trabalho dos profissionais de saúde na promoção da qualidade de vida do idoso, para que o indivíduo tenha um envelhecimento digno ${ }^{(14)}$.

Mais que relacionar o enfermeiro empreendedor apenas à percepçáo e busca de novas oportunidades e negócios, as pesquisas avançam, portanto, no sentido de atribuí-lo a responsabilidade pelas transformaçóes nos ambientes, inclusive sociais ${ }^{(15)}$. $\mathrm{O}$ enfermeiro passa a desempenhar, assim, um importante papel social junto à população 
envelhecida ao assegurar a melhoria da qualidade dos serviços em ILPI's.

Apesar da relevância, observam-se poucos estudos descrevendo as ILPI's brasileiras, principalmente daquelas geridas por enfermeiros. Assim, considerando a escassez na literatura, o presente estudo tem como objetivo geral caracterizar no âmbito comercial as instituiçóes de longa permanência de idosos no Estado de São Paulo e aquelas constituídas por enfermeiros descrevendo o perfil dos enfermeiros empreendedores.

Conhecer informações atuais acerca de possíveis mercados de trabalho junto à populaçáo idosa podem subsidiar projetos pedagógicos na graduação de enfermagem que incluam temas como envelhecimento e empreendedorismo, garantindo maior oferta de serviços a essa crescente população e, ao mesmo tempo, ampliando possibilidades de atuação dos futuros profissionais de enfermagem.

\section{MATERIAL E MÉTODO}

Trata-se de uma pesquisa quantitativa, transversal, de caráter exploratório e descritivo.

A coleta de dados foi efetuada em bancos de dados de acesso público disponibilizados pela Junta Comercial do Estado de São Paulo (JUCESP) e do Conselho Regional de Enfermagem-SP (CORENSP), de empresas e enfermeiros empreendedores registrados até o primeiro semestre de 2017.

A JUCESP é um órgão para-governamental estadual, que tem a função de registrar a abertura de empresas e a fiscalização da situação comercial no Estado de Sáo Paulo. É necessário o protocolo de registro junto à mesma, dentre outras autorizaçóes legais, para a criaçáo de qualquer empreendimento comercial $^{(16)}$. Para a obtenção dos dados, a pesquisadora efetuou o cadastro junto à JUCESP, na condição de cidadão comum, para o acesso público.

Seguindo a Classificação Nacional de Atividades Econômicas - CNAE, baseada nas atividades econômicas relacionadas à saúde humana e serviços sociais, foram selecionadas aquelas mais pertinentes dentro das seguintes divisóes: 86. Atividades de atenção à saúde humana e 87 . Atividades de atenção à saúde humana integradas com assistência social, prestados em residências coletivas e particulares. Buscando maior amplitude da amostra e tendo em vista possíveis erros de digitação nas fichas, foram adotados os descritores "permanência" e "repouso" para identificar empresas para compor a população total do estudo. Tal decisão foi necessária devido às alteraçóes implantadas pelo IBGE na nomenclatura da atividade econômica que passou de "casas de repouso" para "instituiçôes de longa permanência de idosos" a partir de dezembro de $2010^{(17)}$.

Assim, a população do estudo constituiu-se de todas as empresas registradas no Estado de Sáo Paulo, com atividade econômica relacionada às instituiçóes de longa permanência de idosos (antes denominada "casas de repouso"), totalizando 2.029 empresas. Excluídas as empresas identificadas em duplicidade, constituiu-se de forma aleatória a amostra final representativa de 661 empresas, com confiabilidade de $95 \%$ e margem de erro de 3,13\%.

Foram catalogados os dados disponíveis nas fichas cadastrais das empresas que compuseram a amostra, como objeto social completo com todas as atividades desenvolvidas pela mesma, capital social, datas de constituição e início das atividades, tipo de empresa (sociedades limitadas, sociedades anônimas, empresários de responsabilidade limitada, empreendedores individuais ou cooperativas), enquadramento de faturamento (microempresas - ME, empresas de pequeno porte EPP, outros), CNPJ (Cadastro Nacional de Pessoas Jurídicas) e município onde se localizavam. Foram captados ainda os dados dos proprietários como nome, CPF (Cadastro de Pessoas Físicas), função (sócio ou sócio administrador) e participação econômica na empresa.

$\mathrm{Na}$ segunda etapa foi consultado o site do órgáo fiscalizador do exercício profissional em enfermagem, o COREN-SP ${ }^{(18)}$. A partir da identificação das empresas e empresários, foi efetuada consulta dos inscritos no referido conselho de classe, identificando-se ainda a categoria profissional (enfermeiros, técnicos de enfermagem ou auxiliares de enfermagem). Foram coletados números e datas de registro.

Para a análise das empresas, as variáveis selecionadas para o estudo foram o capital social, ano de abertura, tipo de empresa acerca do quadro societário, faturamento e localização. Para análise dos enfermeiros empresários, as variáveis selecionadas foram sexo, ano de registro no COREN, tempo entre a abertura da empresa e o registro no COREN, bem como o tipo de negócio 
de que participavam.

Os dados coletados foram registrados em banco de dados a partir de planilhas do programa Microsoft ${ }^{\oplus}$ Excel. Para a análise dos dados foram realizados cálculos da distribuição da frequência simples e relativa das variáveis.

Foram preservados os aspectos éticos conforme previsto em legislação brasileira. O projeto desta pesquisa foi aprovado pelo Comitê de Ética em Pesquisa da Faculdade de Medicina de Botucatu da UNESP pelos pareceres 2.499.340 e 2.885.923. Só tiveram acesso ao seu conteúdo os membros da equipe de investigação. Todos os dados foram tratados confidencialmente. $\mathrm{O}$ anonimato foi mantido em todo o momento, e os dados somente foram analisados de forma coletiva.

\section{RESULTADOS}

Foram listadas 2.029 empresas registradas, em situação ativa, classificadas como ILPI's ou casas de repouso, sendo a amostra final delimitada em 661 empresas, correspondendo a $32,6 \%$ do total.

Foram localizadas 238 (35,4\%) instituiçôes registradas por profissionais que compoem equipe de enfermagem, ou seja, enfermeiros, técnicos e auxiliares de enfermagem. Cento e trinta empresas (19,7\%) tinham enfermeiros em seu quadro societário. A maioria era composta por dois sócios $(68,0 \%)$, sendo pelo menos um enfermeiro e em $31,0 \%$ da amostra as empresas eram constituídas apenas por um enfermeiro empresário.

Conforme Tabela 1 , com relação ao período de abertura das empresas, constatou-se que 26,6\% foram constituídas até o ano 2000, sendo todas classificadas como casa de repouso. Já a maioria teve suas portas abertas a partir de 2011 ( $n=405$; 61,3\%), sendo somente ILPI's. Esse cenário fica mais evidente nas organizaçóes registradas por enfermeiros, sem nenhuma empresa constituída antes de 1991, com a maioria aberta a partir de 2011 ( $\mathrm{n}=118 ; 90,8 \%)$.

O estudo permitiu identificar a preferência por empresas do tipo sociedade de responsabilidade limitada $(55,5 \%)$ em detrimento àquelas registradas como empresários individuais com e sem responsabilidade limitada (38,7\%). Esses números se elevam significativamente nas empresas de enfermeiros, constituída em sua maioria como sociedades de responsabilidade limitada (73,1\%).

Da análise do capital social das empresas, verificou-se que a maioria das ILPI's (44,0\%) contava com investimento inicial de até $\mathrm{R} \$$ $10.000,00$ (aproximadamente US\$ 2.700) e $28,3 \%$ delas com até R\$ 50.000,00. Poucas possuíam capital superior a $\mathrm{R} \$ 1.000 .000,00$ $(3,9 \%)$. Observou-se que nos empreendimentos de enfermeiros os investimentos eram menores, se alterando para 46,1 e 36,9\%, respectivamente; nenhuma empresa foi constituída com valores de capital social superior a R \$ 180.000,00.

Com relação à classificação fiscal de acordo com o faturamento anual, verificou-se que a grande maioria das instituições analisadas eram microempresas - ME (69,9\%) ou empresas de pequeno porte - EPP $(8,5 \%)$. As demais empresas representavam $21,6 \%$ da amostra. Já naquelas constituídas por enfermeiros graduados, observouse um aumento significativo das ME's (85,4\%).

O município de São Paulo concentrava grande parte das empresas (36,7\%), sendo o restante pulverizado, em menores números, nos demais municípios paulistas. O mesmo ocorreu entre aquelas geridas por enfermeiros $(35,4 \%)$.

Com relação ao perfil dos enfermeiros empreendedores, foram encontrados 150 empresários, entre proprietários individuais $(n=40)$ e sócios de empresas ( $n=110), 23,3 \%$ são homens e a maioria deles se registrou no COREN a partir de 2011 (46,0\%), conforme pode ser verificado na Tabela 2 .

Houve prevalência de enfermeiros que constituíram empresas após seu registro no COREN $(90,7 \%)$, em média 6,1 anos depois da referida inscrição na entidade. No entanto, foram encontrados profissionais que empreenderam antes de seu registro como enfermeiros $(9,3 \%)$, os quais se inscreveram no referido conselho em média 4,1 anos após constituírem suas empresas. 
Tabela 1. Caracterização das ILPI's registradas de acordo com a sua data de abertura, tipo societário ou natureza jurídica, capital social, faturamento e localizaçáo no Estado de Sáo Paulo, Brasil. Botucatu, São Paulo/ Brasil, 2019.

\begin{tabular}{|c|c|c|c|c|c|}
\hline \multirow[t]{2}{*}{ Características } & & \multicolumn{2}{|c|}{$\begin{array}{c}\text { Amostra } \\
\text { Total }(n=661)\end{array}$} & \multicolumn{2}{|c|}{$\begin{array}{c}\text { Empresas de } \\
\text { Enfermeiros } \\
\quad(n=130)\end{array}$} \\
\hline & & $\mathrm{n}$ & $\%$ & $\mathrm{n}$ & $\%$ \\
\hline \multirow[t]{4}{*}{ Período de abertura } & Até 1990 & 62 & 9,4 & 0 & 0 \\
\hline & De 1991 a 2000 & 114 & 17,2 & 5 & 3,8 \\
\hline & De 2001 a 2010 & 80 & 12,1 & 7 & 5,4 \\
\hline & De 2011 a 2017 & 405 & 61,3 & 118 & 90,8 \\
\hline \multirow[t]{5}{*}{ Tipo societário ou natureza jurídica } & Cooperativa & 5 & 0,8 & 1 & 0,8 \\
\hline & Sociedade Anônima & 33 & 5 & 0 & 0 \\
\hline & Eireli* & 53 & 8 & 12 & 9,2 \\
\hline & Empresário Individual & 203 & 30,7 & 22 & 16,9 \\
\hline & Sociedade de Responsabilidade Limitada & 367 & 55,5 & 95 & 73,1 \\
\hline \multirow[t]{7}{*}{ Capital Social } & Até R\$ 10.000,00 & 291 & 44 & 60 & 46,1 \\
\hline & De $\mathrm{R} \$ 10.000,01$ a $\mathrm{R} \$ 50.000,00$ & 187 & 28,3 & 48 & 36,9 \\
\hline & De $\mathrm{R} \$ 50.000,01$ a $\mathrm{R} \$ 100.000,00$ & 82 & 12,4 & 18 & 13,8 \\
\hline & De $\mathrm{R} \$ 100.000,01$ a $\mathrm{R} \$ 500.000,00$ & 23 & 3,5 & 3 & 2,4 \\
\hline & De $\mathrm{R} \$ 500.000,01$ a $\mathrm{R} \$ 1.000 .000,00$ & 3 & 0,5 & 0 & 0 \\
\hline & Acima de $\mathrm{R} \$ 1.000 .000,00$ & 26 & 3,9 & 0 & 0 \\
\hline & Outras moedas ou não mencionado & 49 & 7,4 & 1 & 0,8 \\
\hline \multirow[t]{3}{*}{ Faturamento Anual/ Porte } & $\mathrm{ME} \dagger$ & 462 & 69,9 & 111 & 85,4 \\
\hline & EPP $\ddagger$ & 56 & 8,5 & 11 & 8,5 \\
\hline & Outro $\$$ & 143 & 21,6 & 8 & 6,1 \\
\hline \multirow[t]{2}{*}{ Localização } & Município de São Paulo-SP & 243 & 36,8 & 46 & 35,4 \\
\hline & Outros municípios do Estado-SP & 418 & 63,2 & 84 & 64,6 \\
\hline
\end{tabular}

* Empreendedor Individual de Responsabilidade Limitada (EIRELI).

$\dagger$ Microempresas com faturamento anual abaixo de R $360.000,00$ (ME).

\$ Empresas de pequeno porte com faturamento entre $\mathrm{R} \$ 360.000,00$ e R \$ 4.800.000,00 (EPP).

$\$$ Empresa Normal com faturamento acima de $\mathrm{R} \$ 4.800 .000,00$.

Tabela 2. Caracterização dos enfermeiros empresários de acordo com sexo, tipo negócio, registro no COREN e tempo entre a abertura da empresa e o registro no COREN. São Paulo, Brasil, 2019.

\begin{tabular}{llcc}
\hline Características & & $\mathbf{n}$ & $\mathbf{\%}$ \\
\hline Sexo & Homens & 35 & 23,3 \\
& Mulheres & 115 & 76,7 \\
Tipo de Negócio & Empresários individuais & 40 & 26,7 \\
& Sócios ou cooperados & 110 & 73,3 \\
Registro no COREN como Enfermeiros & Até 2000 & 15 & 10 \\
& 2001 a 2010 & 66 & 44 \\
& 2011 a 2017 & 69 & 46 \\
Constituição da Empresa & Antes de registro no COREN como enfermeiros & 14 & 9,3 \\
& Após registro no COREN como enfermeiros & 136 & 90,7 \\
\hline Totais & & 150 & 100 \\
\hline
\end{tabular}




\section{DISCUSSÃO}

Nosso estudo revelou que a maioria das ILPI's foi constituída a partir de 2011, na forma de sociedade de responsabilidade limitada, com baixo investimento inicial, reduzido faturamento anual, estando presente na maioria dos municípios paulistas, mas com grande concentração na cidade de São Paulo. Apesar do importante papel social ao assegurar melhor qualidade de vida e de serviço ao idoso, poucos enfermeiros empreendem em ILPI's no Brasil e, quando o fazem, seus negócios são de porte menor.

A grande maioria dos profissionais de enfermagem brasileiros se concentra na regiáo sudeste brasileira. Dados atualizados do Conselho Federal de Enfermagem (COFEN) mostram que, dos mais de dois milhóes de inscritos nos conselhos regionais de enfermagem, o estado de São Paulo registra 25\% dos profissionais de todo o Brasil ${ }^{(19)}$. Sendo responsável por $32,2 \%$ do PIB nacional, o estado concentra também 33,38\% das ME e EPP's do Brasil ${ }^{(20)}$. Nesse contexto, a análise do panorama de empreendedorismo na enfermagem no Estado de Sáo Paulo é importante do ponto de vista político e econômico, contribuindo para melhorias nas bases curriculares da graduação e nos aspectos profissionais e de políticas públicas.

A abertura de empresas registradas como ILPI's principalmente a partir de 2011 corrobora com os dados disponibilizados pelo Instituto de Pesquisa Econômica Aplicada (IPEA), únicas informaçóes oficiais sobre o tema, que identificou apenas 1.219 instituiçôes em 2010 no estado, nem todas registradas formalmente ${ }^{(21)}$. Esses dados refletem a história brasileira com o cuidado ao idoso, que passou a ter novas perspectivas efetivas somente no início deste século. De cunho caritativo, até a década de 1970, era desenvolvido por entidades filantrópicas ou religiosas. Apesar dos aspectos do envelhecimento já estarem previstos na Constituição Brasileira de 1988, apenas em 1994 foi estabelecida uma política nacional específica para os idosos, tendo como objetivo garantir os direitos sociais da pessoa idosa, visando sua autonomia, integração e participação efetiva na sociedade ${ }^{(22)}$. A promulgação do Estatuto do Idoso $^{(23)}$ em 2003, a regulamentação pela ANVISA em $2005^{(8)}$ e a adoção de normas técnicas pelas secretarias de saúde estaduais e municipais nos anos subsequentes trouxeram novas e efetivas perspectivas no início deste século. Com os novos marcos legais e a crescente demanda, o número de empreendimentos nessa área passou a aumentar nos anos seguintes, principalmente a partir de 2011. Tais resultados corroboram ainda com estudos de empresas de outras áreas da saúde ${ }^{(24,25)}$, refletindo o impulso gerado também por outros fatores como os incentivos governamentais para desburocratização para abertura de empresas, redução de impostos, formalização de pequenos negócios desde o início do século, entre outros ${ }^{(26-29)}$.

Em relação ao tipo societário ou natureza jurídica, isto é, como é organizada a empresa em torno de seus sócios e as responsabilidades deles com o negócio, os resultados encontrados corroboram com pesquisa de empresas de enfermagem ${ }^{(25)}$, cuja preferência por sociedade com responsabilidade limitada está relacionada à decisão de não comprometer o patrimônio pessoal dos empreendedores, como ocorre em empresas individuais normais. Uma forma de evitar tais sociedades sem comprometer o patrimônio pessoal, seria constituir uma empresa individual de responsabilidade limitada (Eireli), sendo para isso exigido o capital social no valor de, no mínimo, 100 vezes o salário-mínimo do país ${ }^{(30)}$, o que não reflete a realidade financeira da maioria dessas empresas. Por esses motivos grande parte dos empreendedores opta em registrar empresas em conjunto com outro(s) indivíduo(s), ainda que muitos destes não atuem no empreendimento.

O perfil econômico dessas organizaçôes pode ser analisado pelos investimentos iniciais (capital social) e pela classificação fiscal determinada pelo faturamento anual. A maioria das empresas de enfermeiros, como as demais ILPI's foi constituída com baixo investimento inicial (até R \$ 50.000,00) corroborando com estudo anterior onde $96 \%$ das empresas não ultrapassavam esse valor ${ }^{(25)}$. Com faturamento total anual geralmente inferior a $\mathrm{R} \$$ 360.000,00, essas instituiçóes são caracterizadas como microempresas, da mesma forma como evidenciado em pesquisa entre 12.068 empresas de saúde ${ }^{(24)}$. Apesar do tamanho de suas empresas, esses empreendedores podem se revelar verdadeiros agentes socioeconômicos para o desenvolvimento regional e nacional, uma vez que as ME e EPP's são responsáveis por importante percentual da renda e geraçáo de emprego, já que representam 27\% do Produto Interno Bruto e 52\% dos empregos formais do país ${ }^{(29)}$. 
Considerando o baixo faturamento dessas empresas e a possível redução de impostos pela opção por $\mathrm{ME}$, há que se ponderar que, ao empreender numa ILPI, o enfermeiro reduz custos, uma vez que ele mesmo pode responder tecnicamente pela equipe, não sendo necessário contratar outro profissional de saúde para atender às exigências legais, representando a instituição junto à autoridade sanitária local, tendo formação de nível superior e registro no respectivo conselho de classe ${ }^{(8)}$. Tudo isso refletiria também numa maior credibilidade ao empreendimento, ao ser gerido e ter como seu proposto um enfermeiro, isto é, um profissional graduado da saúde.

A localização das empresas em grandes centros urbanos como o município de São Paulo corrobora com estudos anteriores ${ }^{(24,25)}$, uma vez que nessas áreas existem mais recursos e demandas populacionais, não representando, no entanto, restrição às demais cidades, desde que o negócio seja alicerçado em um planejamento adequado e com boa análise de viabilidade.

Com relação ao perfil dos enfermeiros empreendedores, verificamos certa discrepância em relação ao gênero. A porcentagem de enfermeiros empreendedores homens (23,3\%) verificada em nossa pesquisa mostra-se superior à média de enfermeiros no país $(12,8 \%)^{(31)}$ e pode revelar a preferência dos mesmos em áreas gerenciais, o que carece de pesquisas futuras mais aprofundadas. Por outro lado, sendo a maioria das empresas constituídas por mulheres, os dados reforçam o distanciamento do discurso de que mulheres são inferiores aos homens, ou de que a mulher não possa gerenciar uma empresa nas mesmas condiçóes de trabalho, pela cultura da fragilidade ${ }^{(32)}$.

Pesquisa entre proprietários de 2.000 empresas do estado de Sáo Paulo sobre sobrevivência de empresas nascentes relata barreiras à atuação empresarial feminina, especificamente no contexto do lançamento e continuidade de novas empresas, revelando, entretanto, que mulheres se valem de mecanismos compensatórios para aumentar o sucesso do negócio, tais como melhor gestão de recursos como capital humano e social além de práticas gerenciais diferenciadas ${ }^{(33)}$.

Alinhadas às pesquisas recentes sobre empoderamento feminino, teorias modernas de liderança vêm reconhecendo a exigência de atributos tradicionalmente considerados alinhados ao desempenho feminino, como a inteligência emocional, que promove componentes da inovaçáo, crescimento e valor ${ }^{(34)}$. Assim, desenvolver competências gerenciais e para o empreendedorismo (antes consideradas habilidades masculinas), numa profissão predominantemente de mulheres, trará reflexos nas dinâmicas sociais relacionadas a gênero e ao empoderamento feminino.

Além do aspecto financeiro e patrimonial já discutido, a preferência dos enfermeiros empreendedores por atuarem como sócios pode ainda ser decorrente da percepção da complexidade das necessidades de saúde da população idosa, que exige a qualificação para o trabalho colaborativo ${ }^{(8)}$, além daquelas decorrentes da própria gestão do negócio. $\mathrm{O}$ trabalho multiprofissional requerido pelo cuidado ao idoso acaba por gerar interfaces de enfermeiros com outros profissionais da saúde como fisioterapeutas, nutricionistas, fonoaudiólogos, terapeutas ocupacionais, psicólogos, além dos médicos e assistentes sociais. Reconhecidas e regulamentadas a partir do século passado, a maioria dessas profissóes de saúde são relativamente novas e mais empreendedoras, mas, assim como a enfermagem, vêm buscando espaços de atuação no mercado $^{(24)}$, podendo representar oportunidade de parcerias pelo o estabelecimento de redes.

Aliar-se ainda a técnicos ou auxiliares de enfermagem também é considerada como uma opção pelo alinhamento às boas práticas e técnicas em saúde. Tampouco, associar-se a administradores de empresas pode se mostrar útil ao aprendizado para a gestão de uma ILPI. Essa hipótese é suportada por pesquisa realizada com o objetivo de compreender a experiência de enfermeiros empreendedores com ILPI, que concluiu que esse ramo de prestação de serviços ainda se constitui em negócio de risco, por faltar-lhes experiência e conhecimento em gestão empresarial, revelando lacunas no ensino de graduação de enfermagem ${ }^{(35)}$. De modo geral, sociedades poderiam fortalecer a gerência destas organizaçóes, além de gerar resultados positivos nos cuidados dos idosos ali atendidos.

Formados principalmente nos últimos dez anos, enfermeiros formados mais recentemente tendem a empreender em ILPI's, corroborando com estudo mundial do Global Entrepreneurship Monitor (GEM), que avalia o ambiente para o empreendedorismo em 54 países, segundo o qual o Brasil é o único país que tem na faixa 
dos 18 aos 24 anos a sua mais alta taxa de empreendedorismo inicial ${ }^{(36)}$. Tais achados revelam características inerentes às novas geraçôes, tais como necessidade constante de aprendizado, o prazer e a autorrealização, bem como conciliação da vida pessoal com as obrigaçóes profissionais ${ }^{(37)}$. Tais peculiaridades reforçam a necessidade de inserir capacitação nos cursos de graduação relativos às habilidades empresariais, preparando adequadamente os futuros profissionais, expandindo suas opçóes de carreira.

No entanto, a ausência da educação empreendedora na graduação de enfermagem é uma barreira ainda a ser explorada em instâncias de formação acadêmica. Estudos apontam que as universidades continuam focando no gerenciamento da assistência ao paciente em detrimento à gestáo organizacional ${ }^{(38)}$, além de manter estruturas que não possibilitam o desenvolvimento empresarial em áreas como a Enfermagem ${ }^{(39)}$. Por outro lado, ao preparar o enfermeiro para desempenhar o papel de empreendedor na conduçáo de um negócio de ILPI, aproveitar-se-ia a oportunidade de unir os conhecimentos de cuidado e de gestão, alinhandose desempenho, adequação de custos e qualidade de serviços prestados aos idosos.

À vista da importância social do enfermeiro empreendedor em ILPI, torna-se ainda necessário encontrar soluçôes capazes de superar barreiras culturais relacionadas ao contexto histórico-cultural que associa a enfermagem ao assistencialismo e ao cuidado, distanciando-se de aspiraçóes socioeconômicas observadas nas demais profissóes ${ }^{(40)}$. Por isso, novas perspectivas acerca do empreendedorismo na enfermagem devem ser incorporadas e discutidas desde os primeiros anos da graduaçáo.

Como área que se encontra em expansão, o negócio de prestação de serviços relacionados à ILPI nos próximos anos pode representar um importante mercado de trabalho para os profissionais graduados em enfermagem, tanto para aqueles que buscam um emprego como para aqueles que desejam ser proprietários, empreendedores.

Ao transpassar o espectro econômico de negócio, expande-se a visão para questôes sociais que essa atitude empreendedora representará num futuro próximo. Diante do premente envelhecimento populacional e da necessidade de se pensar a integralidade e o melhor cuidado ao idoso, bem como empoderar os jovens como agentes econômicos, sociais e políticos, recomendase a proposição de políticas que desenvolvam suas competências e seu empreendedorismo, através do fortalecimento do ensino e sua combinação com as habilidades de gestão, a fim de preparar melhor os futuros enfermeiros para essa nova realidade ${ }^{(41)}$.

Nossa pesquisa apresenta uma série de limitaçôes. Avaliar uma amostra, das empresas registradas como casas de repouso e ILPI's no Estado de São Paulo podem não representar a sua totalidade. A carência de dados oficiais e estudos atualizados sobre as ILPI's brasileiras bem como aqueles relacionados ao empreendedorismo na enfermagem dificulta a comparação com outras pesquisas. Apesar das limitaçôes impostas, o estudo incorpora novos dados à escassa literatura sobre o tema. Como contribuição, esta investigação reforça a necessidade da inclusão no ensino de enfermagem de uma formação para o desenvolvimento de competências empreendedoras para a gestão de ILPI's, e consequentemente, aumentar a qualidade dos serviços prestados ao idoso.

\section{CONCLUSÓES}

Nosso estudo teve por objetivo caracterizar no âmbito comercial empresas registradas como ILPI's no Estado de São Paulo e aquelas constituídas por enfermeiros, descrevendo o perfil dos enfermeiros empreendedores.

A maioria das ILPI's foi constituída a partir de 2011, na forma de sociedade de responsabilidade limitada, com baixo investimento inicial, reduzido faturamento anual, estando presente na maioria dos municípios paulistas, mas com maior concentração na cidade de São Paulo.

Profissão marcada pela vocação cultural de serviço e atuação, poucos enfermeiros empreendem em ILPI's no Brasil apesar do importante papel social ao assegurar melhor qualidade de vida e de serviço ao idoso. Identificados principalmente por pequenos negócios, com investimento inicial menor e baixo faturamento anual, esses microempreendedores podem exercer, no entanto, uma função relevante na economia local e regional.

Aspectos geracionais dos profissionais de formação mais recente e atributos tradicionalmente considerados alinhados ao desempenho feminino poderiam atuar na gestão positiva dessas instituiçóes. 
Ao transpassar o espectro simplista de negócio, expande-se a visão para questóes sociais que a atitude empreendedora do enfermeiro representará no futuro com o premente envelhecimento populacional e da necessidade de se pensar o melhor cuidado ao idoso. Torna-se necessário empoderar

\section{REFERENNCIAS}

1. Instituto Brasileiro de Geografía e Estatística (IBGE). Projeção da população no Brasil e no Estado de São Paulo [Internet]. Brasilia: IBGE; 2020. [citado 2020 jun 13]. Disponível em: https:// www.ibge.gov.br/apps/populacao/projecao/

2. Oliveira ATR. Envelhecimento populacional e políticas públicas: desafios para o Brasil no século XXI. Espaço Econ. [Internet]. 2016 [citado 2020 jun 13]; (8). Disponível em: http://journals. openedition.org/espacoeconomia/2140

3. Veras RP, Oliveira M. Envelhecer no Brasil: a construçáo de um modelo de cuidado. Cien Saude Colet [Internet]. 2018 [citado 2020 jun 13]; 23(6):1929-1936. Disponível em: http://doi. org/10.1590/1413-81232018236.04722018

4. Miranda GMD, Mendes ACG, Silva ALA. Population aging in Brazil: current and future social challenges and consequences. Rev bras geriatr gerontol [Internet]. 2016 [cited 2020 jun 13]; 19(3): 507-19. Available from: http://dx.doi. org/10.1590/1809-98232016019.150140

5. Gómez-Urrutia V, Royo UP, Cruz CMA. Imagining Families: Gender, Youth, and Diversity in Chile. Affilia [Internet]. 2017 [cited 2020 jun 13]; 32(4):491-503. Available from: https://doi. org/10.1177\%2F0886109917718232

6. Morais HMM, Albuquerque MSV, Oliveira RS, Cazuzu AKI, Silva NAF. Organizaçóes Sociais da Saúde: uma expressão fenomênica da privatizaçáo da saúde no Brasil. Cad Saude Publica [Internet]. 2018 [citado 2020 jun 13]; 34(1): e00194916. Disponível em: https://www.scielosp.org/pdf/csp/ 2018.v34n1/e00194916/pt

7. Coelho VSP, Greve J. As Organizaçóes Sociais de Saúde e o Desempenho do SUS: Um Estudo sobre a Atenção Básica em São Paulo. Dados [Internet]. 2016 [citado 2020 jun 13]; 59(3):867-901. Disponível em: https://dx.doi. org/10.1590/00115258201694

8. Agência Nacional de Vigilância Sanitária (ANVISA). Resolução de Diretoria Colegiada - RDC no 283, de 26 de setembro de 2005. os jovens como agentes econômicos, sociais e políticos, fortalecendo suas competências para o empreendedorismo, por meio do ensino adequado, a fim de preparar melhor os futuros enfermeiros para essa nova realidade.

Regulamento técnico para o funcionamento das instituiçoes de longa permanência para idosos [Internet]. Brasília: ANVISA; 2005 [citado 2020 jun 13]. Disponível em: http://bvsms.saude.gov.br/ bvs/saudelegis/anvisa/2005/res0283_26_09_2005. html

9. Paula RCC, Rodrigues MA, Santana RF. Dimensionamento de pessoal de enfermagem nas instituições de longa permanência para idosos. Enferm Foco [Internet]. 2018 [citado 2020 jun 13]; 9(S1). Disponível em: http://biblioteca. cofen.gov.br/wp-content/uploads/2018/10/ Dimensionamento-de-Pessoal-de-Enfermagemnas-Institui\%C3\%A7\%C3\%B $\%$ es-de-LongaPerman\%C3\%AAncia-Para-Idosos.pdf

10. Rodrigues MA, Santana RF, Paula RCC, Silva MTN, Espirito Santo FH. Exercício profissional de enfermagem em instituiçóes de longa permanência para idosos: estudo retrospective. Texto contexto - enferm [Internet]. 2018 [citado 2020 jun 13]; 27(2):e1700016, Disponível em: http://dx.doi. org/10.1590/0104-070720180001700016

11. Oliveira Bde, Concone MHVB, Souza SRP. A Enfermagem dá o tom no atendimento humanizado aos idosos institucionalizados? Rev Kairós [Internet]. 2016 [citado 2020 jun 13]; 19(1):239-254. Disponível em: https://revistas. pucsp.br//index.php/kairos/article/view/31112/0

12. Lee HY, Blegen MA, Harrington C. The effects of RN staffing hours on nursing home quality: a two-stage model. Int J Nurs Stud [Internet]. 2014 [cited 2020 jun 13]; 51(3):409-17. Available from: https://doi.org/10.1016/j.ijnurstu.2013.10.007

13. Backhaus R, Verbeek H, Van Rossum E, Capezuti E, Hamers JPH. Nurse staffing impact on quality of care in nursing homes: a systematic review of longitudinal studies. J Am Med Dir Assoc [Internet]. 2014 [cited 2020 jun 13]; 15(6):38393. Available from: http://www.sciencedirect.com/ science/article/pii/S1525861013007962

14. Martins AA, Sousa FS, Oliveira KMM, Oliveira FA, Bezerra STF, Barbosa RGB. Conhecendo o perfil clínico do idoso institucionalizado: um olhar sobre a qualidade da assistência. ReTEP Rev Tend 
Enferm Prof [Internet]. 2017 [citado 2020 jun 13]; 9(2): 2176-2181. Disponível em: http://www. coren-ce.org.br/wp-content/uploads/2019/02/ CONHECENDO-O-PERFIL-CL \%C $3 \% 8$ DNICO-DO-IDOSO-INSTITUCIONALIZADO. pdf

15. Franco JOB, Gouvêa JB. A cronologia dos estudos sobre o empreendedorismo. Rev Empreendedorismo Gest Pequenas Empres [Internet]. 2016 [citado 2020 jun 13]; 5(3):144-66. Disponível em: http://www.regepe.org.br/index.php/regepe/ article/view/360/pdf

16. Junta Comercial do Estado de São Paulo (JUCESP). Registro e abertura de empresas [Internet]. São Paulo: JUCESP; 2020 [citado 2020 jun 13]. Disponível em: https://www.jucesponline.sp.gov. br/Default.aspx

17. Instituto Brasileiro de Geografía e Estatística (IBGE). Comissão Nacional de Classificação. Resolução Concla no 1 , de 04 de setembro de 2006. Divulga a Classificação Nacional de Atividades Econômicas CNAE 2.0 [Internet]. Brasilia: IBGE; 2011 [citado 2020 jun 13]. 48 p. Disponível em: https://concla.ibge.gov.br/concla/resolucoes-atas. html

18. Conselho Regional de Enfermagem de São Paulo. Consulta de inscritos [Internet]. São Paulo: Coren; 2020 [citado 2020 jun 13]. Disponível em: https:// portal.coren-sp.gov.br/consulta-de-inscritos/

19. Conselho Federal de Enfermagem. Enfermagem em números [Internet]. Brasília: Cofen; 2020 [citado 2020 jun 13]. Disponível em: http://www. cofen.gov.br/enfermagem-em-numeros

20. Fundaçáo Seade. PIB Anual [Internet]. São Paulo: Seade; 2020 [citado 2020 jun 13]. Disponível em: http://www.seade.gov.br/produtos/pib-anual/

21. Camarano AA (coordenadora). Características das instituiçôes de longa permanência para idosos: Regiăo Sudeste [Internet]. V.5. Brasília, DF: IPEA; 2010 [citado 2020 jun 13]; 240 p. Disponível em: https://www.ipea.gov.br/portal/images/stories/ PDFs/livros/livro_caractdasinstituicoesregiao1.pdf

22. Presidência da República (BR). Casa Civil. Lei ${ }^{\circ}$ 8.842, de 4 de janeiro de 1994. Dispóe sobre a política nacional do idoso, cria o Conselho Nacional do Idoso e dá outras providências [Internet]. Brasília; 1994 [citado 2020 jun 13]. Disponível em: http://www.planalto.gov.br/ccivil_03/leis/188 42.htm

23. Presidência da República (BR). Casa Civil. Lei ${ }^{\circ}$ 10.741, de 1 de outubro de 2003. Dispóe sobre o Estatuto do Idoso e dá outras providências [Internet]. Brasília; 2003 [citado 2020 jun 13]. Disponível em: http://www.planalto.gov.br/ccivil _03/leis/2003/110.741.htm
24. Colichi RMB, Lima SAM. Empreendedorismo na enfermagem: comparação com outras profissōes da saúde. Rev Eletr Enf [Internet]. 2018 [citado 2020 jun 13]; 20. Disponível em: https://doi. org/10.5216/ree.v20.49358

25. Andrade AC, Dal BLW, Sanna MC. Empreendedorismo na Enfermagem: panorama das empresas no Estado de São Paulo. Rev Bras Enferm [Internet] 2015 [citado 2020 jun 13]; 68(1):40-4. Disponível em: http://dx.doi.org/10.1590/00347167.2015680106p

26. Presidência da República (BR). Casa Civil. Lei ${ }^{\circ}$ 9.841, de 5 de outubro de 1999. Institui o Estatuto da Microempresa e da Empresa de Pequeno Porte, dispondo sobre o tratamento jurídico diferenciado, simplificado e favorecido previsto nos arts. 170 e 179 da Constituição Federal [Internet]. Brasília: 1999 [citado 2020 jun 13]. Disponível em: http://www. planalto.gov.br/ccivil_03/leis/L9841impressao. htm

27. Presidência da República (BR). Casa Civil. Lei complementar no 123 , de 14 de dezembro de 2006: Institui o Estatuto Nacional da Microempresa e da Empresa de Pequeno Porte; altera dispositivos das Leis $\mathrm{n}^{\circ} 8.212$ e 8.213 [Internet]. Brasília; 2006 [citado 2020 jun 13]. Disponível em: http://www. planalto.gov.br/ccivil_03/leis/LCP/Lcp123.htm

28. Presidência da República (BR). Casa Civil. Lei complementar no 147 , de 7 de agosto de 2014. [Internet]. Brasília; 2014 [citado 2020 jun 13]. Disponível em http://www.planalto.gov.br/ccivil _03/leis/LCP/Lcp147.htm

29. Cabral S, Reis PRC, Sampaio AH. Determinantes da participação e sucesso das micro e pequenas empresas em compras públicas: uma análise empírica. Rev Adm [Internet]. 2015 [citado 2020 jun 13]; 50(4):477-491. Disponível em: http://www.scielo. br/scielo.php?script $=$ sci_arttext $\&$ pid $=$ S0080 21072015000400477\&lng=en\&nrm=iso

30. Presidência da República (BR). Casa Civil. Lei no 12.441, de 11 de julho de 2011. Altera a Lei ${ }^{\circ}$ 10.406, de 10 de janeiro de 2002 (Código Civil), para permitir a constituição de empresa individual de responsabilidade limitada [Internet]. Brasília; 2011 [citado 2020 jun 13]. Disponível em: http://www.planalto.gov.br/ccivil_03/_ato20112014/2011/lei/l12441.htm

31. Conselho Federal de Enfermagem. Pesquisa perfil da enfermagem no Brasil [Internet]. Brasília: Cofen; 2020 [citado 2020 jun 13]. 750 p. Disponível em: http://www.cofen.gov.br/perfilenfermagem/pdfs/ relatoriofinal.pdf

32. Richter SA, Santos EP, Kaiser DE, Capellari C, Ferreira GE. Açóes empreendedoras em enfermagem: desafios de enfermeiras em posição 
estratégica de liderança. Acta paul enferm [Internet]. 2019 [citado 2020 jun 13]; 32 (1): 46-52. Disponível em: https://dx.doi.org/10.1590/19820194201900007

33. Bertolami M, Artes R, Gonçalves PJ, Hashimoto M, Lazzarini SG. Sobrevivência de Empresas Nascentes: Influência do Capital Humano, Social, Práticas Gerenciais e Gênero. Rev Adm Contemp [Internet]. 2018 [citado 2020 jun 13]; 22(3): 31135. Disponível em: https://doi.org/10.1590/19827849rac2018160121

34. Galloway L, Kapasi I, Sang K. Entrepreneurship, leadership, and the value of feminist approaches to understanding them. JSBM [Internet]. 2015 [cited 2020 jun 13]; 53: 683-92. Available from: https:// doi.org/10.1111/jsbm.12178

35. Trombeta FM, Ramos NP, Bocchi SCM. Experiência de enfermeiros empreendedores com instituiçôes de longa permanência para idosos. Rev Bras Enferm [Internet] 2020 [citado $2020 \mathrm{dez}$ 22]; 73(S3). Disponível em: <http://www.scielo. br/scielo.php?script=sci_arttext\&pid=S0034$71672020001500174 \& \operatorname{lng}=$ en\&nrm=iso >

36. Global Entrepreneurship Monitor (GEM). Emprendedorismo no Brasil: Relatório Executivo 2018 [Internet]. Curitiba, PR: GEM; 2019 [citado 2020 jun 13]. 26 p. Disponível em: http:// datasebrae.com.br/wp-content/uploads/2019/02/ Relat\%C3\%B3rio-Executivo-Brasil-2018-v3-web. pdf
37. Silva RC, Trevisan LN, Veloso EFR, Dutra JS. Career anchors and values from different career management perspectives. Review of Business Management [Internet]. 2016 [cited 2020 jun 13]; 18(59):145-162. Available from: https://doi. org/10.7819/rbgn.v18i59.2260

38. Elango B, Hunter GL, Winchell M. Barriers to nurse entrepreneurship: A study of the process model of entrepreneurship. J Am Acad Nurse Pract [Internet]. 2007 [cited 2020 jun 13]; 19:198-204. Available from: https://doi.org/10.1111/j.17457599.2007.00215.x

39. Lanero A, Vázquez JL, Aza CL. Social cognitive determinants of entrepreneurial career choice in university students. ISBJ [Internet]. 2015 [cited 2020 jun 13]; 34(8):1053-75. Available from: https://doi.org/10.1177\%2F0266242615612882

40. Nikbakht-Nasrabadi A, Shabany-Hamedan M. Providing healthcare services at home - a necessity in Iran: a narrative review article. Iran J Public Health [Internet]. 2016 [cited 2020 jun 13]; 45(7):867-74. Available from: https://www.ncbi. nlm.nih.gov/pmc/articles/PMC4980340/

41. OCDE/ECLAC/CAF. Latin American Economic Outlook 2017: Youth, Skills and Entrepreneurship [Internet]. Paris: OECD Publishing; 2016 [cited 2020 jun 13]. Available from: http://www.keepeek. com/Digital-Asset-Management/oecd/development /latin-american-economic-outlook-2017_leo2017-en\#.WnNydq6nHct\#page3 